\title{
lipophilic halogen-free ionic liquid with antibacterial and anti-biofilm activities against Pseudomonas aeruginosa
}

\author{
Kris Corinne DC. Laserna ${ }^{1}$, Christian Deo T. Deguit ${ }^{1}$, Wilfred F. Ong ${ }^{1}$, and Drexel H. Camacho ${ }^{1,2^{*}}$ \\ ${ }^{1}$ Chemistry Department, De La Salle University, 2401 Taft Avenue, 0922 Manila \\ ${ }^{2}$ Organic Materials and Interfaces Unit, CENSER, De La Salle University, 2401 Taft, Avenue, Manila
}

\begin{abstract}
A halogen-free ionic liquid (IL) designed with long alkyl chain anion is reported. 1-methylimidazolium stearate (MIM stearate) synthesized through Bronsted acid-base reaction has shown improved lipophilic character and indications penetrate bacterial cell walls. Antimicrobial activities against Gram-negative bacteria, Escherichia coli, and Pseudomonas aeruginosa were observed. Anti-biofilm assays showed effectivity against the biofilm of Pseudomonas aeruginosa. At $50 \mu \mathrm{g} / \mathrm{mL}$ the \%biofilm inhibition of MIM stearate towards $P$. aeruginosa biofilm formation is comparable to the Bromofuran positive control. Brine shrimp lethality assay showed weak toxicity indicating the IL to be safe and benign. The synthesized MIM stearate showed good promise as an antimicrobial and anti-biofilm agent.
\end{abstract}

Keywords: ionic liquid; imidazolium stearate; halogen-free ionic liquid; antimicrobial; anti-biofilm; lipophilic

\section{INTRODUCTION}

Biofilm, a group of microorganisms encased in an extracellular polymeric substance (EPS) is a survival strategy for microbial populations. It poses an industrial, environmental, health and economic hazard because biofilms cannot be removed by gentle rinsing affecting the form, fit and function of the substrates they attached unto. Moreover, the EPS, a gel matrix made up of polysaccharides, proteins, lipids, and other macromolecules holds the microorganisms together making them resistant to antimicrobial treatments (Flemming 1996; Bridier et al. 2011). Biofilm-mediated complications such as functional failures of implanted medical devices, biocorrosion of industrial structures and chronic infection to humans, animals, and plants, have been a major problem (Lewis, 2001; Costerton
\& Wilson, 2004). Thus the efficient control of microbial biofilms is of particular interest. There has been an active search for potent compounds that can effectively inhibit biofilm formation. However, effective anti-biofilm agents that are safe and environmentally benign are hard to find. Plant extracts (Kodali et al. 2013; Upadhyay et al. 2013; Viju et al. 2013, Riihinen et al. 2014) and bacterial polysaccharides (Bernal \& Llamas 2012; Karwacki et al. 2013; Kavita et al. 2014) have been reported to inhibit biofilm formation but the mechanism is unknown. Nanoparticles (Kanmani \& Lim, 2013; Lee et al. 2014; Taglietti et al. 2014) and enzymes (Burton et al. 2006; Gawande et al. 2011) have been reported to alter the extracellular polymeric substance (EPS) in biofilms making it susceptible to antimicrobial treatments. A simple compound that can penetrate into the EPS and deliver the active 
agent to kill the microorganism is highly desired.

Ionic liquids are of high interest as they have been shown to have many possible beneficial applications. Contrary to salts, which exist in crystalline form, ionic liquids are ionic compounds (salts) that exist in liquid form below $100^{\circ} \mathrm{C}$. These liquids have unique physicochemical characteristics that enable them to possess many useful properties as safe and benign solvents in "green chemistry", as catalysts in organic transformation, as agents in chiral synthesis, as electrical conductors, as lubricants, as electroplating agents, etc. (Stark et al. 2013). Recent studies have shown that ionic liquids inhibit the growth of certain parasites (Vlahakis et al. 2010) and bacteria (Gilmore 2011). It has also been demonstrated to inhibit biofilm formation (Sekhon 2011; Busetti et al. 2010; Ferraz et al. 2011, Gilmore, 2010). However, a cursory survey of the literature reveals no reports of a halogen-free ionic liquid that are active against microorganisms. Thus, the exciting possibility of the use of ionic liquids as green bactericidal and anti-biofilm agents can be studied.

In designing an ionic liquid as an anti-bacterial and anti-biofilm agent, it must contain an active component and must be able to penetrate into the EPS and bacterial cell wall. Imidazole and its derivatives are very potent fungicides and enzyme inhibitors that interfere with the microorganism's cellular mechanisms (Shalini et al. 2010). The reported studies on the potency of alkylimidazolium compounds against microorganisms are limited to imidazolium halides, where the anions are halogens (Yu \& Nie 2011). It is surmised in this current work that organic anions are better antimicrobial and anti-biofilm agents because the lipophilic character of organic anions enables them to penetrate the EPS and bacterial cell wall better than halides. Also, ionic liquids with organic anions are not commonly reported in the literature and a lot of potentials is seen in the synthesis of these compounds. A onestep synthesis of lipophilic, halogen-free ionic liquid (1-methylimidazolium stearate) and its antimicrobial and anti-biofilm activities is reported herein.

\section{MATERIALS AND METHODS}

Melting point was determined on a Fischer Scientific melting point apparatus and was uncorrected. The ${ }^{1} \mathrm{H}$ and ${ }^{13} \mathrm{C}$ NMR spectra were recorded on a Bruker Avance 300 using TMS as the internal standard and $\mathrm{CDCl}_{3}$ as a solvent. $\mathrm{J}$ values are given in $\mathrm{Hz}$. FTIR spectrum was recorded on Thermo Scientific ${ }^{\text {TM }}$ Nicolet $^{\mathrm{TM}}$ iS $^{\mathrm{TM}} 10$ FTIR spectrometer using $\mathrm{KBr}$ method and mass spectral analysis was done on Bruker microTOF-Q2 Mass Spectrometer. The instruments used for the anti-biofilm activity are the Tuttnauer autoclave, Memmert oven, incubator (Julabo SW22 Shaking Water Bath) and microtiter plate reader (BioTek ELx800 Absorbance Reader).

\section{Synthesis of 1-methylimidazolium stearate (MIM stearate) [1]. Equimolar amounts of} stearic acid (5.688 g; Aldrich) were reacted with 1-methylimidazole (1.6402 g; Aldrich) in $75 \mathrm{~mL}$ ethyl acetate, stirred at room temperature under $\mathrm{N}_{2}$ for $24 \mathrm{hrs}$. The solvent was removed under reduced pressure, washed several times with small portions of ethyl acetate to remove unreacted starting materials, and dried under vacuum at $70-80{ }^{\circ} \mathrm{C}$ to yield 1 , which is a yellow liquid product at $80^{\circ} \mathrm{C}$, but paleyellow solid at room temperature.

1-methylimidazolium stearate (1) (6.37g, 87.0\%), mp $53.7{ }^{\circ} \mathrm{C}$. FTIR: $v_{\max } / \mathrm{cm}^{-1} 3390 \mathrm{br}, 3138 \mathrm{~m}$, $3113 \mathrm{~m}, 2953 \mathrm{w}, 2916 \mathrm{~s}, 2850 \mathrm{~m}, 2622 \mathrm{w}, 1709 \mathrm{~s}$, $1590 \mathrm{w}, 1472 \mathrm{~s}, 1466 \mathrm{~s}, 1414 \mathrm{w}, 1333 \mathrm{w}, 1282 \mathrm{~m}$, 1102s, 1085s.; ${ }^{1} \mathrm{HNMR}: \delta \mathrm{H}\left(400 \mathrm{MHz}, \mathrm{CDCl}_{3}\right.$, $\left.\mathrm{Me}_{4} \mathrm{Si}\right): \delta 0.85(3 \mathrm{H}, \mathrm{t}, \mathrm{J}=5.6) 1.26(28 \mathrm{H}, \mathrm{s}), 1.61$ $(2 \mathrm{H}, \mathrm{m}, \mathrm{J}=5.6), 2.29(2 \mathrm{H}, \mathrm{t}, \mathrm{J}=5.6), 3.68(3 \mathrm{H}$, s), $6.85(1 \mathrm{H}, \mathrm{d}, \mathrm{J}=0.8), 7.05(1 \mathrm{H}, \mathrm{d}, \mathrm{J}=0.4), 7.62$ $(1 \mathrm{H}, \mathrm{s}), 8.52(1 \mathrm{H}, \mathrm{s}) .{ }^{13} \mathrm{C}$ NMR: $\delta \mathrm{C}(500 \mathrm{MHz}$, $\left.\mathrm{CDCl}_{3}, \mathrm{Me}_{4} \mathrm{Si}\right): 179.57,137.75,128.09,120.28$, $34.36,33.77,32.07,29.84,29.82,29.80,29.75$, $29.60,29.51,29.42,29.26,24.94,22.84,14.26$ ppm. HRMS calcd for $\mathrm{C}_{4} \mathrm{H}_{7} \mathrm{~N}_{2}{ }^{+}\left(\mathrm{ESI}^{+}\right)$: 83.115, found: 83.0598; HRMS calcd for $\mathrm{C}_{18} \mathrm{H}_{35} \mathrm{O}_{2}$ (ESI-): 283.4679 , found: 283.2655 .

Antimicrobial activity. Antimicrobial activity was done using paper disk diffusion assay and was tested against Gram-negative (Escherichia coli, Pseudomonas aeruginosa) and Gram-positive (Bacillus subtilis, Staphylococcus aureus) bacteria. Paper (Whatman No. 3) disks were soaked in $30 \mu \mathrm{g} / \mathrm{mL}$ of 1 and compared with Ceftazidime ( $30 \mu \mathrm{g} / \mathrm{mL}$; positive control) and deionized water (negative control).

Toxicity Assay. The Brine shrimp (Artemia salina) lethality bioassay for toxicity study was done according to Sharma et al. (2013). A stock solution $(2 \mathrm{mg} / \mathrm{mL})$ of 1 in increasing amount $(0.25,0.50$, $0.75,1.00,1.25,2.50,3.75 \mathrm{~mL}$ ) was tested in 15 live nauplii and compared against synthetic sea water (negative control) and potassium dichromate solution, $2 \mathrm{mg} / \mathrm{mL}$ (positive control) in three replicates.

Anti-biofilm assay. All glassware were sonicated with detergents, rinsed thoroughly with acetone, methanol, and water successively and dried in the oven. The Petri plates wrapped in paper were autoclaved at 15 psi at $120^{\circ} \mathrm{C}$ for 30 minutes and allowed to cool inside the autoclave. The anti-biofilm 
assays were done using the two-fold serial dilution test in a 96-well microtiter plate (Falcon 353072, polystyrene, tissue culture treated by vacuum gas plasma), and was determined by using colorimetric assay (Burton et al. 2007). MIM stearate 1 was tested against Pseudomonas aeruginosa PAO1 in triplicates. MIM stearate 1 was dissolved in distilled deionized $\mathrm{H}_{2} \mathrm{O}$ containing $0.2 \%$ DMSO and subjected to serial dilutions of $100 \mu \mathrm{L}$ in different concentrations from 3.125 to $50 \mu \mathrm{g} / \mathrm{mL}$. The mixtures of 1 with the bacteria $\left(1.5 \times 10^{8} \mathrm{cfu} / \mathrm{mL}\right)$ in Tryptic soy broth media were incubated at $37^{\circ} \mathrm{C}$ for $24 \mathrm{~h}$. After incubation, the media were gently removed and the microtiter plates were washed, dried and stained with $0.4 \%$ crystal violet following the control protocol described by Burton et al. (2007). Microbial growth particularly detection of cell optical density was examined by measuring the absorbance at $630 \mathrm{~nm}$ with a microtiter plate reader (BioTek ELx800 Absorbance reader). The $\mathrm{H}_{2} \mathrm{O} / \mathrm{DMSO}$ was used as a blank and bromofuran as the positive control. The \% Biofilm Inhibition Index (\%BII) was calculated using [a]. The $\mathrm{IC}_{50}$ was determined using the equation of the line from the $\%$ BII graphs [b] where $\mathrm{y}=50$.

$$
\begin{gathered}
B I I, \%=100-\left(\frac{O D_{630}, \text { treated }}{O D_{630}, \text { untreated }} \times 100\right) \\
I C_{50}=x=\frac{y-b}{m}, \text { where } y=50
\end{gathered}
$$

Biofilm eradication - Time Dependent Inbibition Assay. From the subculture of bacteria, a $100 \mu \mathrm{L}$ aliquot was transferred to each well of the 96-well flat-bottomed microtiter plate and the plates were incubated at $37^{\circ} \mathrm{C}$ for $24 \mathrm{hrs}$ to form biofilms. The unbound microorganisms or the planktonic form of the bacteria was removed and the biofilm was exposed to or co-incubated with $100 \mu \mathrm{L}$ of the MIM stearate ionic liquid, dissolved in $0.2 \% \mathrm{DMSO}$ with different concentrations $(50.0,25.0,12.5,6.25$, and $3.12 \mu \mathrm{g} / \mathrm{mL}$ ) for 6,12 , and $24 \mathrm{~h}$ at $37^{\circ} \mathrm{C}$. For positive control, 95\% EtOH was used while 0.2\% DMSO was used for the negative control. After coincubation, the compounds were removed gently and the wells were washed with Phosphate-buffered saline (PBS) solution three times. The plates were airdried for 15 mins before staining with $0.4 \%$ crystal violet for another 15 minutes at room temperature. The unbound crystal violet stain was removed and the wells were washed gently with PBS solution. The wells were air dried again for 15 mins and $100 \mu \mathrm{L}$ of $33 \%$ acetic acid was used to solubilize the bound stain. The plates were read spectrophotometrically at $630 \mathrm{~nm}$ using a microtiter plate reader.

\section{RESULTS}

The ionic liquid we designed as anti-bacterial and anti-biofilm agent includes imidazolium cation owing to its antimicrobial properties, and a long chain stearate anion owing to its non-polar and hydrophobic property. The long alkyl chain anion was designed to allow easy penetration into the EPS so that the antimicrobial imidazolium cation, can be delivered inside the biofilm and interact with the bacterial cells and its environment.

The synthesis of ionic liquids usually requires two steps involving a quaternization reaction followed by metathesis anion exchange reaction (Clare et al. 2010). Other methods require enhancements using a microwave or ultrasonic irradiation (Cravotto et al. 2008; Aupoix et al. 2010; Tran et al. 2014). This work presents a one-pot synthesis where 1-methylimidazole was simply added to the stearic acid solution in ethyl acetate. A color change occurred from clear white solution to yellow after $24 \mathrm{hrs}$ reaction. Upon solvent removal, whiteyellow solids, which has a sharp melting point of $53.7^{\circ} \mathrm{C}$ was produced. This melting point is different from the melting points of the starting materials (1-methylimidazole: $-60{ }^{\circ} \mathrm{C}$ and stearic acid: $69.4{ }^{\circ} \mathrm{C}$ ). The solids produced are considered an ionic liquid because the melting point is still below $100{ }^{\circ} \mathrm{C}$. The product, 1-methylimidazolium (MIM) stearate $\mathbf{1}$, is a new ionic liquid classified as "Bronsted acidic imidazolium"-based IL due to the presence of hydrogen atom on the imidazolium nitrogen. The long alkyl chain in the stearate anion induces efficient stacking causing the molecule to solidify at room temperature. NMR, FTIR and mass spectral data indicate successful synthesis. Tuneability of ionic liquids offers much flexibility in terms of designing chemicals for functionality. The stearate anion in $\mathbf{1}$ provides a lipophilic character that can be exploited for specific applications such as antimicrobial and anti-biofilm activities.

The antimicrobial activity data indicate that $\mathbf{1}$ is selective to Gram-negative bacteria (Table 1). No zones of inhibition were observed for Gram-positive bacteria. Carson et al. (2009) reported that Gramnegative bacteria are more susceptible to ionic liquids as compared with fungi and Gram-positive bacteria. The susceptibility of Gram-negative bacteria may be caused by their relatively thin peptidoglycan layer in their cell walls compared to Gram-positive bacteria.

The ability of MIM stearate $\mathbf{1}$ to inhibit biofilm formation on polystyrene microtiter plate surface was determined against the Gram-negative bacteria P. aeruginosa (Figure 1). Results indicate a general decrease in optical density (OD630nm) where OD 


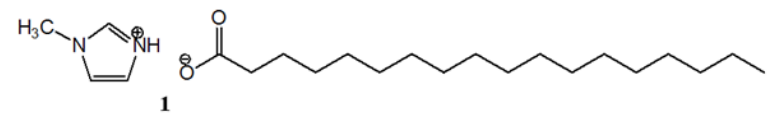

Table 1. Zones of inhibition ( $\mathrm{mm})$ using disk diffusion assay.

\begin{tabular}{lllll}
\hline & E. coli & P. aeruginosa & B. subtilis & S. aureus \\
\hline IL 1 & 8.67 & 10.67 & 6.00 & 6.00 \\
\hline+ control & 19.0 & 12.33 & 21.3 & 15.33 \\
\hline - control & 6.00 & 6.00 & 6.00 & 6.00 \\
\hline
\end{tabular}

${ }^{*}$ Diameter of the paper disk is $6.00 \mathrm{~mm}$. All experiments were run in triplicates. + control is Ceftazidime $(30 \mu \mathrm{g} / \mathrm{mL})$ and negative control is deionized water.

is a measure of bacterial growth. The higher the OD, the more bacteria thrive. At the concentrations tested $(3.125 \mu \mathrm{g} / \mathrm{mL}-50 \mu \mathrm{g} / \mathrm{mL})$, the biofilm inhibitory effect of MIM stearate $\mathbf{1}$ is below the untreated wells, indicating positive inhibition. Using ANOVA ( $95 \%$ confidence level), there's no significant difference in terms of the ability to inhibit biofilm formation between 1, and bromofuran at $50 \mu \mathrm{g} / \mathrm{mL}$ (Fcalc: 0.678; Fcrit: 3.316)

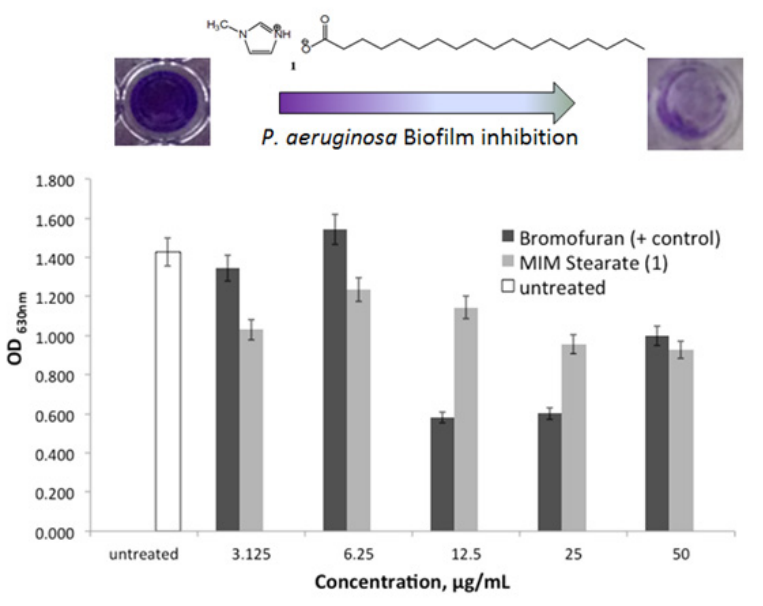

Figure 1: Optical Density at $630 \mathrm{~nm}$ of P. aeruginosa upon Addition of Bromofuran (positive control), and MIM stearate 1 at Various Concentrations.

The biofilm inhibition index of MIM stearate 1 on $P$. aeruginosa (Figure 2 ) was further investigated and the results show that the $\% \mathrm{BII}$ is positive at lower concentration and gradually increases as the concentration increases. It is noticeable that the linear trend of the negative control (0.2\% DMSO) has a negative slope suggesting ineffective antibiofilm activity. To investigate the effect of the type of the anion and cation in biofilm activity, analog compounds were prepared and tested such as sodium stearate $(\mathrm{NaSt})$, potassium iodide $(\mathrm{KI})$ and 1-ethyl-3-methylimidazolium iodide ([EMIM] $[\mathrm{I}])$. In comparing the \%BII of [EMIM][I] and
KI on $P$. aeruginosa, generally, the presence of an alkylimidazolium cation improves or has a more potent anti-biofilm activity compared to Group IA cations. The presence of stearate anion in NaSt allows better \%BII compared to halides (KI) confirming that the long alkyl chain anion plays a very critical penetrability role.

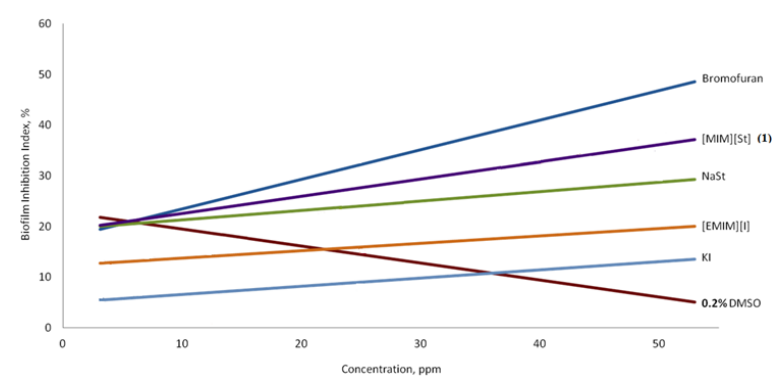

Figure 2. \% Biofilm Inhibition Index of P. aeruginosa Using Crystal Violet Staining - Colorimetric Assay, Read Spectrophotometrically at $630 \mathrm{~nm}$.

The time-dependent eradication assay of $P$. aeruginosa using MIM stearate 1 is shown in Figure 3. Compared to the untreated wells a difference in optical density (OD630nm) was observed upon exposure to the test compound. During the first 6 hours thin biofilms are formed and as the time increases to 12 and 24 hours, thicker biofilms $(-35 \mu \mathrm{m})$ are formed protecting the bacteria. The protective effect of biofilms allows bacteria to increase. This is noticeable for the untreated well where optical density of $P$. aeruginosa increases over time. Upon treatment with $\mathbf{1}$, there is only a slight increase in OD between 6-24 hours. The observed OD at 24 hours for wells treated with $\mathbf{1}$ is significantly different from the untreated well. Within different concentrations of $\mathbf{1}$, a general trend of decreasing OD as the concentration of $\mathbf{1}$ increases confirming the biofilm inhibition index to occur at higher concentration.

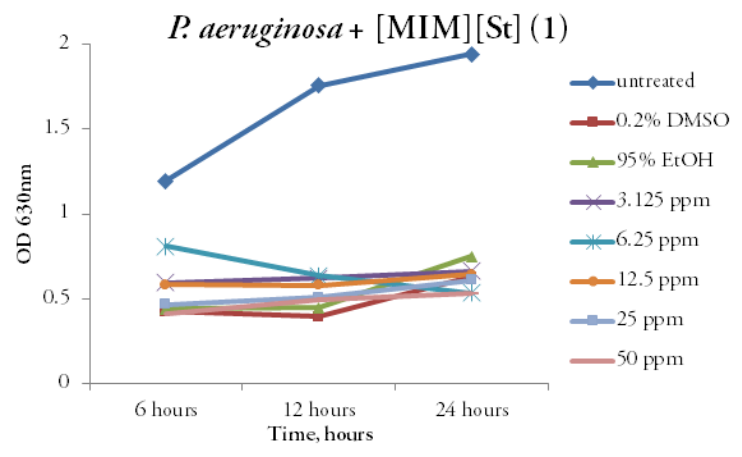

Figure 3. Time-dependent Eradication Assay of P. aeruginosa with Various Concentration of MIM stearate 1; 95\% EtOH (+ control), and 0.2\% DMSO (- control). 
The $\mathrm{IC}_{50}$ of the compounds were tested (Figure 4) for anti-biofilm activity against $P$. aeruginosa. A significant difference was observed (Fcalc: 4.454; Fcrit: 18.513) when the $\mathrm{IC}_{50}$ values of sodium stearate $(\mathrm{NaSt})$ and $\mathrm{KI}$ were compared using ANOVA (95\% confidence level). The $\mathrm{IC}_{50}$ of $\mathrm{NaSt}$ is lower than that of KI indicating that the stearate ion is a better anion to use in designing an ionic liquid for anti-biofilm activity purposes. Lipophilicity has a large effect on the anti-biofilm activity of the ionic liquids. Comparing the $\mathrm{IC}_{50}$ of [EMIM][I] and [MIM][St], the latter has lower $\mathrm{IC}_{50}$, a significant difference (Fcalc: 41267; Fcrit: 161), making it a more effective anti-biofilm agent than the halide containing ionic liquid. The result confirmed the significance of the long alkyl chain in anti-biofilm activity. MIM stearate showed no significant difference with the positive control in terms of antibiofilm activity.

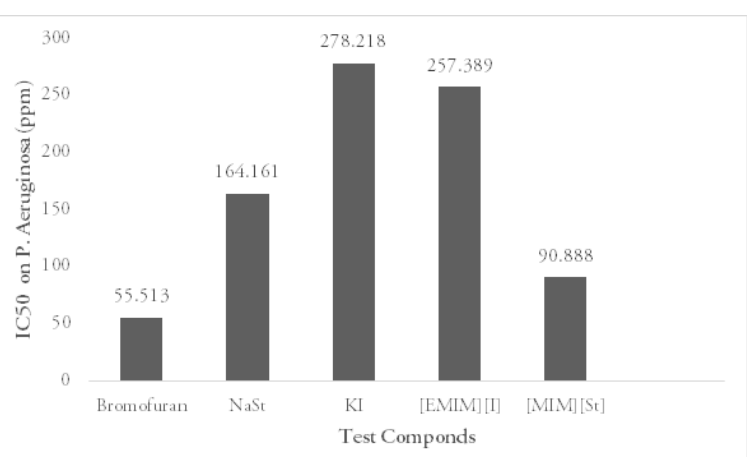

Figure 4. IC ${ }_{50}$ of the Test Compounds on P. aeruginosa.

Preliminary mechanism-of-action studies indicate that the ionic liquid prevents the formation of a fully developed biofilm specifically during the initial phase of biofilm development. Generally, the ionic liquid activity against microorganism is through membrane disruption as a result of interaction with the cell wall and membrane (Docherty \& Kulpa 2005). Biofilm formation is triggered when the cell density population of the microorganisms reached a certain threshold. The microorganisms send signaling molecules or autoinducers (AI), which are responsible for the growth and spread of the biofilm. This cell signaling system called quorum sensing (QS), is responsible for biofilm formation. The primary route (QS 1) for biofilm formation in $P$. aeruginosa is known and operates through the las system composed of LasI/LasR genes where LasI is the AI synthase enzyme and LasR is the transcriptional activator (Glansdorp et al, 2004). This QS system directs the synthesis of the signal molecule $N$-(3oxododecanoyl) homoserine lactone (2) (Glansdorp et al., 2004) which in terms of molecular structure is quite similar to MIM stearate $\mathbf{1}$. The characteristic alkyl chain of the stearate ion, which is similar to the acyl homoserine lactone $\mathbf{2}$ can penetrate into the EPS and into the cell, delivering the known antibacterial imidazolium ion, which then binds to the receptor protein, disrupting the biofilm formation process by stopping the activation of genes that trigger biofilm formation.

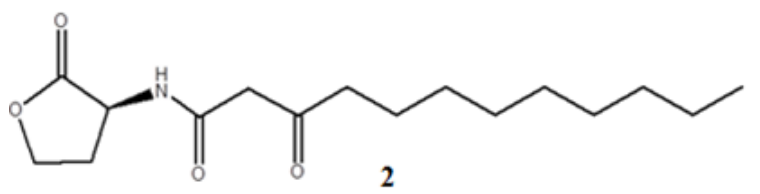

This disruption has shown to be related to the imidazolium cation, and the stearate anion plays a pivotal role of having a high affinity for the bacterial cell membrane due to its lipophilic character (Yaganza et al. 2009). Moreover, the structural similarities of the cation-anion pairs in $\mathbf{1}$ with surfactants, pesticides, and antibiotics suggest disruptive action on bacterial attachment on a surface leading to the inhibition of biofilm formation (Bernot et al. 2005).

To assess the toxicity of $\mathbf{1}$ for safety and environmental reasons (Pham et al. 2010), brine shrimp toxicity assay showed that $\mathbf{1}$ is weakly toxic $\left(\mathrm{LC}_{50}=559 \mu \mathrm{g} /\right.$ $\mathrm{mL})$ as compared to the positive control $\left(\mathrm{LC}_{50}=\right.$ $<90 \mu \mathrm{g} / \mathrm{mL}$; strongly toxic) after 24 hours. Toxicity studies on halide-based imidazolium ionic liquid suggest higher toxicity on the imidazolium ions with longer alkyl chain (Yu \& Nie 2011). In the absence of alkyl chain on the imidazolium nitrogen, the chloride analog of $\mathbf{1}$ has also been reported as moderately toxic against algal cell $P$. subcapitata and non-toxic against $D$. rerio and $D$. magna (Pretti et al. 2009). The lipophilic stearate ion in 1 played a critical role in reduced toxicity since fatty acid-like salts have been shown to exhibit altered toxicity as a result of ions present in water (Kadono et al. 2006).

In summary, the facile synthesis of a designer ionic liquid with long alkyl chain on the anion was demonstrated on 1-methylimidazolium stearate. The lipophilic character introduced on the new ionic liquid is designed to penetrate lipoidal biomembrane. The antimicrobial assay showed selective antimicrobial activity against Gram-negative bacteria Escherichia coli and Pseudomonas aeruginosa. Antibiofilm assay against $P$. aeruginosa showed effective activity comparable with the bromofuran control. Toxicity studies indicate the ionic liquid to be relatively safe and benign. The unique and specific antimicrobial and anti-biofilm activities of MIM stearate $\mathbf{1}$ indicate the strong potential of MIM stearate as a green anti-biofilm coating on surfaces such as in medical devices to prevent device-related infections by pathogens. 


\section{ACKNOWLEDGMENT}

The authors gratefully acknowledge the DLSUURCO for financial assistance and the guidance extended by Mr. Glen Oyong and Dr. Esperanza Cabrera of DLSU-CENSER for the microbiological assays. Dr. Andrew Tangonan is acknowledged for the NMR analysis.

\section{REFERENCES}

Aupoix A, Pégot B, Vo-Thanh G. Synthesis of imidazolium and pyridinium-based ionic liquids and application of 1-alkyl-3-methylimidazolium salts as pre-catalysts for the benzoin condensation using solvent-free and microwave activation. Tetrahedron. 2010; 66:1352-1356.

Bernal P, Llamas MA. Promising biotechnological applications of antibiofilm exopolysaccharides. Microb Biotechnol. 2012; 5:670-673.

Bernot RJ, Kennedy EE, Lamberti GA. Environ Toxicol Chem. 2005; 24:1759-1765.

Bridier A, Briandet R, Thomas V, Dubois-Brissonnet F. Resistance of bacterial biofilms to disinfectants: a review. Biofouling. 2011; 27:1017-1032.

Burton E, Gawande PV, Yakandawala N, LoVetri K, Zhanel GG, Romeo T, Friesen AD, Madhyastha S. Antibiofilm activity of GlmU enzyme inhibitors against catheter-associated uropathogens. Antimicrob Agents Chemother. 2006; 50:18351840.

Burton E, Yakandawala N, LoVetri K, Madhyastha MS. A microplate spectrofluorometric assay for bacterial biofilms. J Ind Microbiol Biotechnol. 2007; 34: 1-4.

Busetti A, Crawford DE, Earle MJ, Gilea MA, Gilmore BF, Gorman SP, Laverty G, Lowry AF, McLaughlin M, Seddon KR. Antimicrobial and antibiofilm activities of 1-alkylquinolinium bromide ionic liquids. Green Chem. 2010; 12: 420-425.

Carson L, Chau PKW, Earle MJ, Gilea MA, Gilmore BF, Gorman SP, McCann MT, Seddon KR. Antibiofilm activities of 1-alkyl-3methylimidazolium chloride ionic liquids. Green Chem. 2009; 11: 492-497.

Clare B, Sirwardana A, Macfarlane DR. Synthesis, purification and characterization of ionic liquids. Top Curr Chem. 2010; 290:1-40.

Costerton WJ, Wilson M. Introducing Biofilms.
Biofilms. 2004; 1:1-4.

Cravotto G, Gaudino EC, Boffa L, Lévêque JM, Estager J, Bonrath W. Preparation of second generation ionic liquids by efficient solvent-free alkylation of $\mathrm{N}$-heterocycles with chloroalkanes. Molecules. 2008; 13:149-156.

Docherty KM, Kulpa Jr CF. Toxicity and antimicrobial activity of imidazolium and pyridinium ionic liquids. Green Chem. 2005; 7: 185-189.

Flemming HC. The forces that keeps biofilms together. In: Sand W, editor. Biodeterioration and Biodegradation. Dechema Monographs Weinheim: VCH Verlagsgesell-Schaft; 1996; 133 p. 311-317.

Ferraz R, Branco LC, Prudencio C, Noronha JP, Petrovski Z̆. Ionic liquids as active pharmaceutical ingredients. ChemMedChem. 2011; 6: 975-985.

Gilmore BF. Antimicrobial Ionic Liquids. Chem Eng News. March 15, 2010; p, 88.

Gilmore BF. Antimicrobial Ionic Liquids. In: Kokorin A, editor. Ionic Liquids: Applications and Perspectives, InTech: Rijeka, Croatia; 2011; p. 587604.

Gawande PV, Yakandawala N, Lovetri K, Madhyastha S. In vitro antimicrobial and antibiofilm activity of Dispersin $^{\odot}$-Triclosan wound gel against chronic wound-associated bacteria. Open Antimicrob Agents J. 2011; 3:12-16.

Glansdorp FG, Thomas GL, Lee JK, Dutton JM, Salmond GP, Welch M, Spring DR. Synthesis and stability of small molecule probes for Pseudomonas aeruginosa quorum sensing modulation. Org Biomol Chem. 2004; 2:3329-36.

Kadono T, Uezu K, Kosaka T, Kawano T. Altered toxicity of fatty acid salts in green paramecia cultured in different waters. Z. Naturforsch C. 2006; 61:541547.

Kanmani P, Lim ST. Synthesis and characterization of pullulan-mediated silver nanoparticles and its antimicrobial activities. Carbohydr Polym. 2013; 97:421-8.

Karwacki MT, Kadouri DE, Bendaoud M, Izano EA, Sampathkumar V, Inzana TJ, Kaplan JB. Antibiofilm activity of Actinobacillus pleuropneumoniae serotype 5 capsular polysaccharide. PloS One. 2013; 8: e63844. 
KavitaK, Singh VK, Mishra A, Jha B. Characterisation and anti-biofilm activity of extracellular polymeric substances from Oceanobacillus iheyensis. Carbohydr Polym. 2014; 101:29-35.

Kodali VP, Karlapudi AP, Kotam M, Kota RK, Punati T, Byri RB. Plant Extracts as Antibiofilm Agents. Int J Pharm Sci Rev Res. 2013; 21:325-328.

LeeJH, Kim YG, Cho, MH, Lee J. ZnO nanoparticles inhibit Pseudomonas aeruginosa biofilm formation and virulence factor production. Microbiol Res. 2014; 169:888-896.

Lewis K. Riddle of Biofilm Resistance. Antimicrob Agents Chemother. 2001; 45:999-1007.

Pham T, Phuong T, Cho CW, Yun YS. Environmental fate and toxicity of ionic liquids: a review. Water Res. 2010; 44:352-372.

Pretti C, Chiappe C, Baldetti I, Brunini S, Monni $\mathrm{G}$, Intorre L. Acute toxicity of ionic liquids for three freshwater organisms: Pseudokirchneriella subcapitata, Daphnia magna and Danio rerio. Ecotoxicol Environ Saf. 2009; 72:1170-1176.

Riihinen KR, Ou ZM, Gödecke T, Lankin DC, Pauli GF, Wu CD. The antibiofilm activity of lingonberry flavonoids against oral pathogens is a case connected to residual complexity. Fitoterapia. 2014; 97:78-86.

Shalini K, Sharma PK, Kumar N. Imidazole and its biological activities: A review. Chem Sin. 2010; $1: 36-47$.

Sharma N, Gupta PC, Singh A, Rao CV. Brine shrimp bioassay of pentapetes phoenicea linn. and ipomoea carnea jacq. leaves. Der Pharmacia Lettre. 2013; 5:162-167.

Sekhon BS. Ionic liquids: Pharmaceutical and Biotechnological Applications. Asian J of Pharm Biol Res. 2011; 1:395-411.

Stark A, Wild M, Ramzan M, Azim MM, Schmidt A. Current Trends in Ionic Liquid Research. In: Brockel U, Meier W, Wagner G, editors. Product Design and Engineering: Formulation of Gels and Pastes. Wiley-VCH Verlag GmbH\&Co KGaA, Germany; 2013; pp. 169.

Taglietti A, Arciola CR, D'Agostino A, Dacarro G, Montanaro L, Campoccia D, Cucca L, Vercellino M, Poggi A, Pallavicini P, Visai L. Antibiofilm activity of a monolayer of silver nanoparticles anchored to an amino-silanized glass surface. Biomaterials 2014; 35:1779-88.
Tran AN, Van Do TN, Le LPM, Le TN. Synthesis of new fluorinated imidazolium ionic liquids and their prospective function as the electrolytes for lithiumion batteries. J Fluorine Chem. 2014; 164:38-43.

Upadhyay A, Upadhyaya I, Kollanoor-Johny A, Venkitanarayanan K. Antibiofilm effect of plant derived antimicrobials on Listeria monocytogenes. Food Microbiol. 2013; 36:79-89.

Vlahakis JZ, Lazar C, Crandall IE, Szarek WA. AntiPlasmodium activity of imidazolium and triazolium salts. Bioorg. Med. Chem. 2010; 18:6184-96.

Viju N, Satheesh S, Vincent SGP. Antibiofilm activity of coconut (Cocos nucifera Linn.) husk fibre extract. Saudi J Biol Sci. 2013; 20:85-91.

Yaganza E, Tweddell R, Arul J. Physicochemical basis for the inhibitory effects of organic and inorganic salts on the growth of pectobacterium carotovorum subsp. Carotovorum and pectobacterium atrosepticum. Appl Environ Microbiol. 2009; 75:1465-1469.

Yu Y, Nie Y. Toxicity and antimicrobial activities of ionic liquids with halogen anion. J Environ Prot. 2011; 2:298-303. 